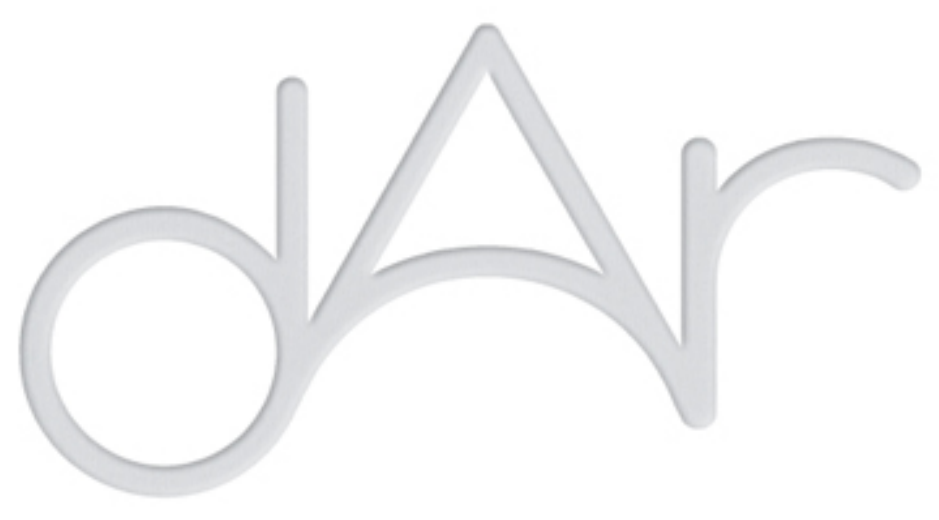

O corpo como memória do pó da terra: uma leitura partir do Orto do Esposo
Autor(es): $\quad$ Henriques, Marisa das Neves
Publicado por: Centro de Estudos em Arqueologia, Artes e Ciências do Património
URL persistente:
URI:http://hdl.handle.net/10316.2/39305
DOI:
DOI:http://dx.doi.org/10.14195/2182-844X_2_10

Accessed : $\quad$ 26-Apr-2023 05:46:47

A navegação consulta e descarregamento dos títulos inseridos nas Bibliotecas Digitais UC Digitalis, UC Pombalina e UC Impactum, pressupõem a aceitação plena e sem reservas dos Termos e Condições de Uso destas Bibliotecas Digitais, disponíveis em https://digitalis.uc.pt/pt-pt/termos.

Conforme exposto nos referidos Termos e Condições de Uso, o descarregamento de títulos de acesso restrito requer uma licença válida de autorização devendo o utilizador aceder ao(s) documento(s) a partir de um endereço de IP da instituição detentora da supramencionada licença.

Ao utilizador é apenas permitido o descarregamento para uso pessoal, pelo que o emprego do(s) título(s) descarregado(s) para outro fim, designadamente comercial, carece de autorização do respetivo autor ou editor da obra.

Na medida em que todas as obras da UC Digitalis se encontram protegidas pelo Código do Direito de Autor e Direitos Conexos e demais legislação aplicável, toda a cópia, parcial ou total, deste documento, nos casos em que é legalmente admitida, deverá conter ou fazer-se acompanhar por este aviso.

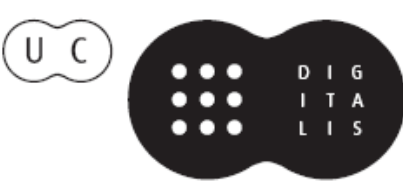




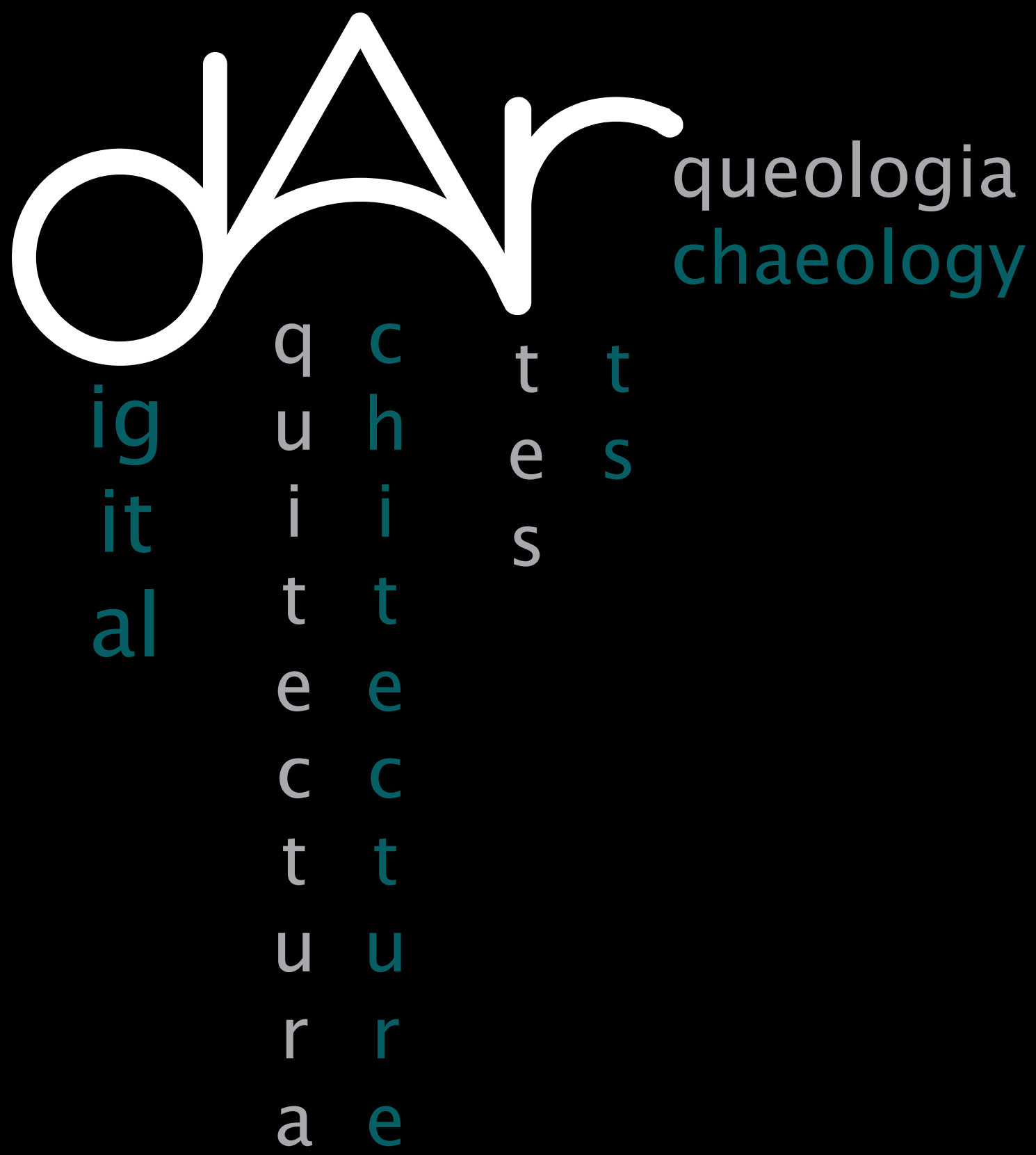




\title{
O CORPO COMO MEMÓRIA DO PÓ DA TERRA - UMA LEITURA A PARTIR DO ORTO DO ESPOSO
}

\author{
Marisa das Neves Henriques* \\ CLP - Centro da Língua Portuguesa \\ UC - Universidade de Coimbra
}

\section{RESUMO}

O Orto do Esposo, obra medieval portuguesa, de caráter místico e de teor teológico-filosófico, produzida por um monge cuja identidade ainda hoje se desconhece, é a obra que propomos trazer à reflexão nas próximas linhas.

Apesar de não conter uma única iluminura nem de revelar aparentes motivos de interesse artístico, é uma obra que, à semelhança do Jardim das Delícias de Bosch, aqui evocado a certa altura, encerra uma imagética do corpo não negligenciável.

Depois de apresentar otimisticamente o espaço edénico colocado à disposição do homem, a narrativa muda o seu curso e o tom de escrita, enveredando por um pessimismo antropológico estreitamente ligado à lembrança da desobediência de Adão e Eva às recomendações divinas. Daqui decorre uma visão crua e impiedosa do corpo, cúmplice do pecado e da mundaneidade, que tentaremos analisar com base em excertos textuais mais significativos e à luz da sensibilidade cristã.

Palavras-chave: Alma, Corpo, Desprezo do Mundo, Paraíso, Pecado, Sentidos

\begin{abstract}
In the next lines we intend to analyze Orto do Esposo, a Portuguese medieval work, which mystical and philosophical roots point to a religious author, whose identity is still obscure.

Despite not having a single miniature, neither arousing artistic interest, it is a work that, not unlike Bosch's Garden of Earthly Delights (mentioned in this article), encompasses an image of the body that is not to be neglected.

After an optimistic presentation of the heavenly space at the disposal of man, the narrative changes its path and tone, heading towards anthropological pessimism that is strongly connected to the memory of the disobedience of Adam and Eva towards divine recommendations. This leads to a raw, ruthless vision on the body, seen as an accomplice to sin and mundanity, which one will try to analyse, based on textual excerpts more significant on the light of a christian sensibility.
\end{abstract}

Keywords: Soul, Body, Contempt for the World, Paradise, Sin, Senses 
"... Pedro Damim, duc de Ueneza, avia hũa sua molher que viuia tam dilicadamẽte e tam uiçosamẽte, que se nõ queria lauar çõ as aguas das fontes nẽ doutros lugares com que se acustumauã lauar os homẽs, mas os seus seruos lhe apanhauã, donde quer que podiam, o orualho que caya do ceeo pera se lauar cõ elle. E os mãjares que auia de comer, nõ os tangia cõ as suas mããos mas cõ colhares douro os comia e cõ outros estormentos [douro]. A sua camara era toda cõprida de odores preciosos de tantas especias e de fumaduras, que era cara cousa de dizer. Mas, sẽẽdo ella uiua, o seu corpo per juizo do Senhor Deus apodreceo ẽ tal guisa que toda a camara ẽchia de tal fedor, que o nõ podiam sofrer. (...) E aquella dona a pouco tẽpo morreo daquella ẽfirmidade en grande amargura, porque se pagou muyto das delectaçõões e uiços corporaaes."

(Orto do Eposo:345)

Leitores e ouvintes desta narrativa extremamente curta, inserta no Orto do Esposo,' têm acesso a uma imagem muito nítida do corpo, que nem o orvalho nem o incenso poupam da mais hedionda degradação. A dama que em cada gesto corpóreo colocara toda a delicadeza e requinte descurou a saúde da alma, precipitando-se para a morte, ainda manifestada em vida, sob os cuidados da única criada que aceitou ampará la, nesses dias agónicos, e aos olhos de quem quisesse daí extrair uma lição.

Mas, deixemos por ora a malograda duquesa italiana e a cena doméstica que protagoniza para tentarmos refletir um pouco sobre a ideia do corpo como memória do pó da terra a partir da leitura do $O E$, obra situável entre finais do século XIV e o princípio do século XV, e que chegou até nós através de dois manuscritos alcobacenses. ${ }^{2}$ Nenhum dos códices revela particular desvelo artístico, à exceção do uso de cores (amarelo, azul, vermelho e violeta) para destacar determinadas iniciais no alc. 198. Quase acidentalmente, este mesmo manuscrito ostenta alguns desenhos realizados nas margens de vários fólios, de entre os quais salientamos uns pequenos dedos (aguçados e curiosos), que apontam para auctoritates citadas no texto, acusando ser o indício material da presença do leitor do momento e a concretização dos seus sublinhados mentais.
Apesar deste despojamento ornamental, que, a comprovar-se a proveniência cisterciense da obra, respeitaria a parcimónia aconselhada por Bernardo de Claraval, o texto é fértil em imagens literárias que se imbricam com a iconografia medieval, aquela que durante séculos fez brotar da mão de talentosos artistas iluminuras de rara beleza. Desde a representação verbal do mirífico jardim inspirado no Cântico dos Cânticos e enriquecido por minuciosas descrições do Paraíso, passando pelo debuxo de espécimes da fauna e da flora, a partir da apresentação das suas características físicas e comportamentais mais impressivas, que evocam elementos decorativos de bestiários e obras enciclopédicas medievais, até à visão disfórica e crua do homem, na sua condição de mortal fragilidade e repugnância escatológica, vislumbram-se razões suficientes para associar o texto do OE a um legado iconográfico eivado de sugestões de influência religiosa e profana.

Tal como o Jardim das Delícias de Bosch, também ele portador de uma densa narrativa, particularmente desenvolvida em relação à fonte da excitação dos sentidos corporais, e que culmina no acesso a um degrau descendente para a humanidade, o OE dedica o extenso Livro IV à expiação humana dos pecados - com sede no corpo -, embora, ao contrário do que se perspetiva na tela, a obra literária anuncie a redenção final, num outro espaço paradisíaco, que sacie os sentidos espirituais e anule a carne, sinédoque do corpo.

Na verdade, são significativas as afinidades filosóficas e teológicas que se estabelecem entre o texto monástico português e o tríptico de Hieronymus Bosch, uma vez que, independentemente das diferentes linguagens artísticas utilizadas e da distância temporal que separa as duas criações, ambas dão a conhecer o inferno ao seu público, numa derrisória acusação dos efeitos perversos do prazer e dos desregramentos mundanais cometidos no jardim luxurioso.

O que a estridência da cor e o efeito sinestésico de Bosch avivam e denunciam, 
embebidos numa simbólica da época que recorre à cultura popular neerlandesa, de tradição oral, as palavras disfémicas do autor monástico português escalpelizam e reprovam, para mostrarem uma terrível imagem do corpo e do corpóreo com assinatura cristã. deteriora a imagem inaugural de ordem e felicidade oferecida pelo jardim edénico. Nessa estação áurea, a criatura humana faz jus ao seu Criador revelando-se digna do espaço em que habita:

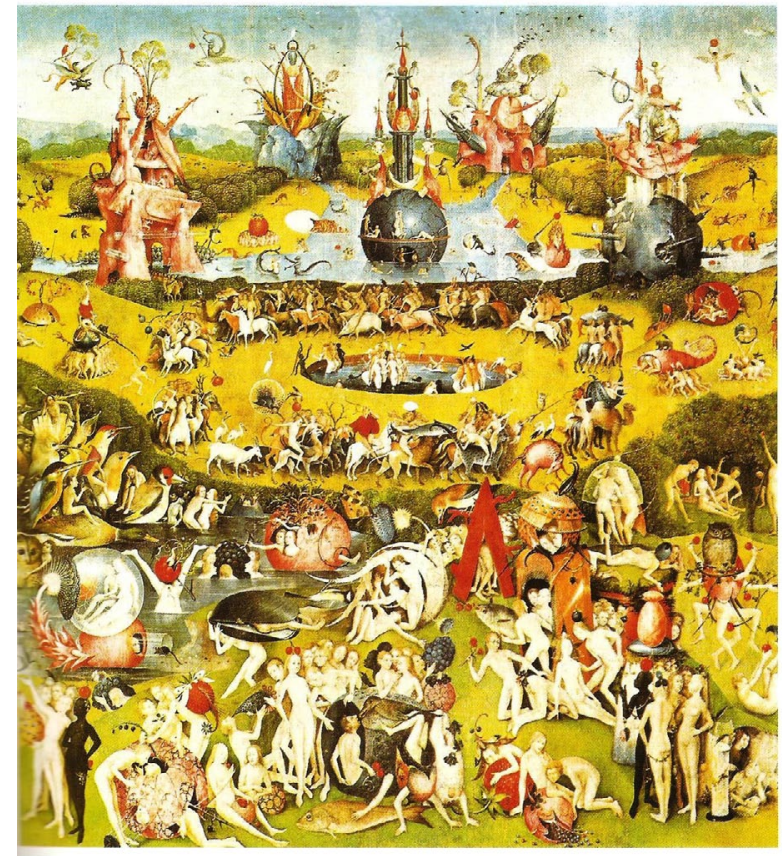

Fig.1 - Bosch, Jardim das Delícias (1480-1490), Painel central.

A tessitura narrativa do OE desenvolvese em três cenários (Éden, falso Paraíso, Inferno) tal como o quadro boschiano, embora no livro se entreabram as portas do céu, desvelando os horizontes de uma possível salvação, ao passo que na tela se topa com a consumação multifacetada do castigo.

Depois de ter sido introduzido num idílico horto paradisíaco, de matriz clássica e bíblica, o leitor é colocado diante de uma figura humana (OE: 57) pouco abonatória que se entrega às tentações da carne e ao vão conhecimento, expondo-se à baixeza física e moral. Na verdade, este retrato é ampliado no Livro IV, cujo pano de fundo temático é o contemptus mundi. Aí, o corpo parece funcionar simultaneamente como lugar e marca do tempo, através do qual o miasma da passagem terrena pelo mundo
"Adam, primeyro homẽ, morador do parayso, principe do linhagẽ humanal, fecto aa ymagẽ de Deus, prelado de todalla[s] cousas que deu nome aas creaturas e recebeo senhoryo sobre ellas, este foy posto ẽnos dileitos do parayso florido, antre os boscos das especias de bõõ odor e antre $\mathrm{a}[\mathrm{s}]$ matas uerdes, e moraua ẽnos canpos cheeos de flores, fazendo sua uida noua cõ prazer e sempre uerde como ẽ uerãão perpetuu". (OE:84)

Mas, "ẽçuyado pelo ẽgano do diaboo e pela língua da femea" (OE: 84), cedo o homem se condena pela ousadia dos seus atos, tornando-se pó da terra e manjar dos vermes. ${ }^{3}$ Ecoa nestas palavras, muitas vezes repetidas ao longo da obra, o vaticínio do versículo genesíaco 3,19 proferido após a queda de Adão (És pó, e ao pó voltarás), a que se há de acrescentar a voz desencantada de Job, presença assídua nesta parte do escrito monástico, ${ }^{4}$ 
bem como o eco do canto magoado do Salmista (cf. Ps. 37,3-11).

Concebido em pecado original, o homem surge envolto, desde a nascença, num manto de contrariedades que o aproximam de vestígios terrenos perecíveis e espúrios como o restolho, o feno, o vapor (OE:175), ou o lodo e a cinza ${ }^{5}$ :

“... o homẽ he fecto de terra, cõcibido ẽ culpa e nado pera pena. Formado he o homẽ do poo e do lodo e da ciinza e ajnda doutra muy uil e muy çuya cousa, concebido he em feruor de luxuria e ẽ grande fedor..." (OE: 91). ${ }^{6}$

Por conseguinte, o corpo, mau conselheiro (OE: 122), liga-se à transitoriedade e à sedução pelos bens temporais (OE: 95) e assume a forma de um vaso corrupto e sujo (OE:97) que coloca em perigo a liberdade da alma, por ser "como carne grave e pesada ao spiritu" (OE:121). Fiel à ideia neoplatónica do corpo como cárcere, ${ }^{7} \mathrm{O}$ autor português só aceita a união da alma com o Esposo, via salvífica do processo de restauração espiritual, até porque os bens corporais - "fremusura e fortaleza e saude, nobreza e liuridõ" - (OE:147) a retêm, anquilosada no patamar da labilidade. Se é certo que a formosura não dura mais do que as flores do verão (OE:148), também o corpo do pecador não ultrapassa a condição de sepultura da alma, ${ }^{8}$ pois o que "jaz so a pelle" (OE:147-148) é repugnante e as graças corporais revelamse desgraçadamente mesquinhas (OE:348).

Entre as várias propostas de libertação dos grilhões que fixam o homem à matéria há um traço em comum - a busca da leveza, que o caminho a percorrer com os pés da alma anuncia:

“...em vez do correr dos pees corporaaes ẽ este mũdo lodoso e fedorẽto, deue o homẽ escolher ẽ esta uida presente correr cõ os pees dedentro da alma, que som o ẽtedimẽto e a afeyçõ...".

(OE: 169)

Os outros pés, aqueles que calçam sandálias e se envolvem na poeira, conduzem, pelo contrário, os homens para itinerários lúdicos desviantes (de jogos e danças), verdadeiras "redes" usadas pelo "diaboo pera tomar a alma dos sandeus" (OE:169). Perante tamanhos ardis que ameaçam, a todo o instante, a integridade espiritual das criaturas de Deus, urge adotar atitudes de abnegação e de desprendimento.

Assim, se a carne for subjugada' transporá o estado servil, preferindo às vestes "molles e preciosas" - verdadeiro "sepulcro cayado defora e dedentro cheo de çugidade" (OE: 326) - a "vestidura rude", sacrificial que eleva. Os panos de sirgo devem substituir as roupagens do século e o ser humano deve envergar a sobriedade e o despojamento, escolha feita pelo senhor "muy nobre e de grande poder e muy rico" que surge no exemplum do capítulo XIII. ${ }^{10}$

Apresentado ao mundo em estado de nudez, fruto impuro do ventre feminino (OE: 99), o homem é um ser para a morte (OE: 91), que retorna à terra na mais pura miséria ontológica, caso não rompa a ligação com o corpo:

"Asy como sayo nuu do uẽtre da sua madre, assy se tornara e nõ leuara nẽhũa cousa do que trabalhou. Mizquinha, ẽfirmidade de todo ẽ todo. Assy como ueo, assy se tornara." (OE: 104) ${ }^{11}$

Não admira, por isso, que a aparência e a beleza corporal sejam desvalorizadas, pois, para além de efémeras (OE:147), revelam ser a porta dileta de entrada do pecado. As principais frinchas desse possível desvio são os cinco sentidos, "castellos guerreyros contra a alma do homẽ" (OE:151), que, excitados pela malha de tentações lançada pela mulher, ${ }^{12}$ aprisionam o espírito. É que, se a obra monástica não abona a favor da figura masculina, vilipendiada pela relação que mantém com a mundaneidade, não é menos acutilante a leitura misógina do vulto feminino, estilhaçado por um pessimismo colhido em Hugo de São Victor e em outras autoridades monásticas.

Assim, o nosso autor trata de condenar os sentidos, um a um, entre os capítulos XVIII e XXII, começando por criticar os olhos, um dos maiores inimigos da alma que "ẽflamã e acendem a luxuria" (OE:153). Além de 
enumerar as vantagens da fealdade, faz o elogio da cegueira física, que entrava o apego aos bens terrenos e refreia sentimentos indignos como a vaidade e a inveja.

Se a visão concupiscente, que se fixa apenas no exterior, desvia o homem da contemplação, também o ouvido corporal compromete os arroubos da alma extática (OE:159). Por essa via sensitiva o homem torna-se permissivo, através do enlevo da música e dos cantares femininos, ao divertimento e à secundarização da mente em relação ao corpo (OE: 160). Com efeito, aquele que é surdo desde o berço, parece ser mais venturoso do que quem ouve perfeitamente, porque escapa ao visco lançado pelos aduladores ${ }^{13}$ e às melodias enganadoras dos "tangeres mũdanaaes" (OE: 160).

Outra das prescrições que encontramos nestas páginas é a de fugir dos odores e sensações olfativas incendiárias que acicatam as más paixões, através do recurso a um salvífico antídoto: a inspiração espiritual do aroma dos corpos dos santos e das suas relíquias. A lembrança do cheiro "de lilios e de rrosas e de cinamomõ e de balsamo"(OE: 164) do jardim de Sião e o perfume do nome de Deus (oleum effusum nomen tuum) devem anular a atração humana por "odores naturaaes" demasiado presos à realidade terrena.

No capítulo XXII, apresentam-se os efeitos perversos que irradiam da boca e dos pés. A boca deve ser silenciada para que a voz interior exprima "a fala dedentro secreta, muyto mais doce e mais blanda que a defora" (OE: 168). De nada servem a boca, os lábios ou a língua para o estabelecimento da comunicação íntima: é o coração que se exprime em silêncio e permite ao mudo "falar cõ tanta multidõõ de sanctos e cõ pessoas tam dignas" (OE: 168). Da mesma forma, hão de brotar do peito as razões afetivas que façam sorrir e derramem sobre os lábios ${ }^{14}$ o prazer de amar a Deus.

Jacob da Pérsia, mártir barbaramente desmembrado, representa aqui o exemplo máximo de renúncia ao corpo, proferindo, no último suspiro de vida, palavras que celebram a libertação desse velho ónus que o acompanhara: "O Senhor Deus me vistira de carne noua, a qual nõ poderõ magoar as uossas chagas"(OE:173).

À verdadeira graça de ter todos os sentidos corporais embotados (OE:167), acrescentase a de ser doente, já que a fragilidade física é sinal de eleição divina, e dom de proximidade relacional com o céu. ${ }^{15} \mathrm{O}$ corpo enfermo habitua-se a sofrer com paciência, sem ser acometido pela soberba (OE:149) nem acorrer voluptuosamente ao espetáculo do mundo, no qual, segundo St. Agostinho,

“... aqueelles que se querem alegrar cõ as cousas defora da alma, ligeyramẽte esuaecem e espargen-se e som derramados e espedaçados ẽ aquellas cousas que parecem e nõ som e lanben as ymagẽẽs ẽno espelho ou que parecẽ em sonho...”. (OE:130)

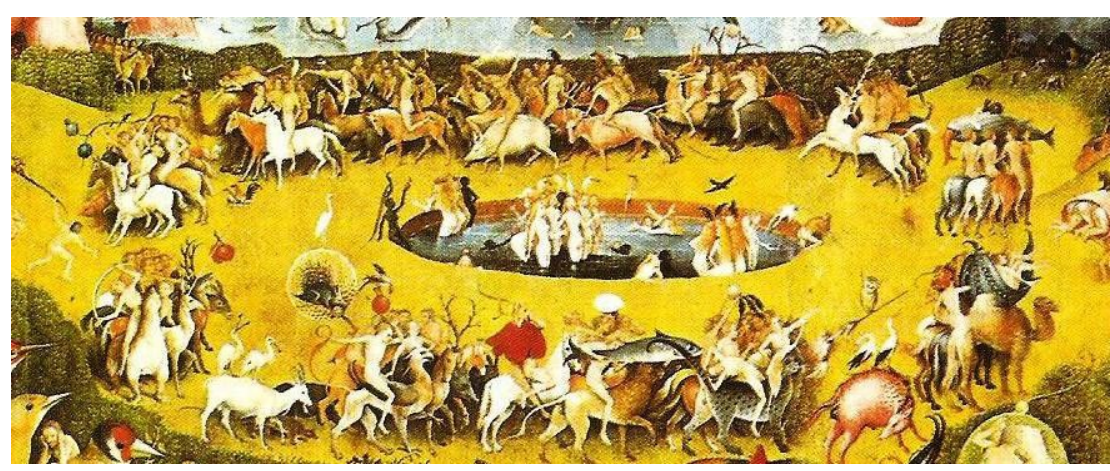

Fig.2 - Bosch, Jardim das delícias (pormenor do painel central). 
Não estamos longe da atmosfera retratada por Bosch no painel central do Jardim das Delícias. Aí, as figuras humanas, nuas e despudoradas, protagonizam cenas lúbricas, envolvendo-se eroticamente, numa cumplicidade que se estende a animais, flores e frutos. Parece brotar dessa ocupação incestuosa e agressiva do espaço alegórico um imenso ruído, talvez aquele que o autor português antevia no corpo saudável e na excitação dos sentidos.

Com efeito, o vigor físico e o alheamento face ao frágil estatuto do corpóreo parecem convidar à hybris e à perversidade, que tanto o autor português como o pintor neerlandês temem. Parece possivel encontrar alguma validade para esta afirmação através da realização de um exercício de comparação. Se olharmos para um pormenor do painel central de Bosch, mais precisamente para a cena que se desenvolve em torno do pequeno lago (onde várias mulheres se banham), circundado por homens que montam a cavalo e, depois de o observarmos com acuidade, cotejarmos a sua semântica com um passo da obra monástica portuguesa

“o homẽ, quando he sãão ẽno corpo, anda folga[n] do pelos canpos uerdes e pelos montes e pelas serras e per matas, caçando o[s] ceruo[s] e os gamos e as outras bestas feras e as aves. Mas o ẽfermo do corpo nõ pode esto fazer. E porẽ podera, se quiser, fazer outras cousas mayres e milhores. Quanto elle he meos poderoso de ssayr aas cousas de fora, que som transitorias e falecidoyras, tanto mais podera emtrar aas cousas dedentro da alma e sobir per entrada emcuberta aas cousas celestriaes e perdurauees...". (OE:177)

não parece difícil encontrar pontos de interceção entre as duas manifestações artísticas, unidas por um objetivo comum, de denúncia e reprovação da luxúria.

O deleite e a fruição temidos pelo nosso autor anónimo são abertamente denunciados no Jardim das Delícias de Bosch, onde se representam gestos que lembram atos venatórios, mas que aludem à dominação sexual. Aproximamo-nos também, nesse sentido, do "sagrado de transgressão" descrito por Roger Callois quando fala do topos da festa, numa dinâmica cíclica de abrandamento temporal, ameaça de estagnação e ciclo de regeneração (1988: 165) que sucede ao tempo "sagrado de regulação", permeado de interditos.

A imagem do corpo e do corpóreo que se extrai dos dois autores não podia ser mais desencantada nem depreciativa. $\mathrm{Na}$ verdade, o OE podia inserir-se entre os títulos que engrossariam a História do corpo na ldade Média, especialmente o capítulo assente no binómio Quaresma /Carnaval (Le Goff: 2005, 29-76). É que vislumbra-se no seu pessimismo ontológico o desprezo como conduta de vida e como forma de habitar o corpo que, lembrado da sua condição de fragilidade - anunciada no Génesis e bradada aos céus por Job - deve sacudir o pó dos pés da alma e tecer com etérea imaginação grinaldas de flores e esquecimento de si próprio.

\section{Notas}

(1) As citações são feitas com base em MALER, Bertil. (ed.). (1956). Orto do Esposo, Rio de Janeiro: Ministério da Educação. Doravante a obra será apresentada pela sigla OE.

(2) Posteriormente foram encontradas várias tiras e um fragmento da obra, descoberta que é documentada por ASKINS, Arthur, L.-F., DIAS, Aida \& SHARRER, Harvey L. (2002). Fragmentos de Textos Medievais Portugueses da Torre do Tombo. Lisboa: IAN/TT.

(3) OE, op. cit., Livro IV, cap. 1, p. 92: "E será fecto manjar do vermem que sempre roe e sempre come e nunca morre. E é massa de pudrimento que sempre fede e sempre é çuja e espantosa."

(4) É notória a força ilocutória de versículos como 14, 1-2 (O homem nascido da mulher vive pouco tempo e está cheio de misérias. É como uma flor que germina e logo fenece, uma sombra que foge sem parar.) ou 18, 13-16 (O sepulcro será a minha morada, nas trevas prepararei o meu leito. Direi à podridão: «Tu és meu pail». E aos vermes: "Vós sóis a minha mãe e a minha irmã». Onde está a minha esperança? Quem verá a minha felicidade? Descerão comigo ao sepulcro, e nos afundaremos juntos no pó?)

(5) Job 30, 19: Sou reputado como lodo e assemelhado ao pó e à cinza. 
(6) E, um pouco mais adiante, op. cit., Livro IV, cap. III, p. 97: "Que cousa he o homẽ senõ lodo e ciinza? E porẽ diz [o homẽ a]o Senhor Deus: Senhor, lenbra-te de my̆, que me fezeste asy como lodo e tornar-me-as depois ẽ poo. E o Senhor Deus disse ao homẽ: Tu es ciinza e ẽ ciinza seeras tornado."

(7) OE, op. cit., Livro IV, cap. II, p. 88: "E como quer que o spiritu he muy agrauado e pessado pella cõpanha da carne, pero elle guarda o seu carcel, e porẽ nõ pode seer liure, segundo diz Sancto Agostinho."; Vd. ainda OE, op. cit., Livro IV, Cap. III, p. 98.

(8) OE, op. cit., Livro IV, cap. XVII, p. 147:

"Prymeyramẽte a fremusura do corpo nõ he muyto pera louuar nẽ prezar, porque tostemẽte trespassa. E o corpo do homẽ he assy como sepulcro, onde diz Sancto Agostinho que o corpo do pecador he moymẽto da alma morta."

(9) OE, op. cit., Livro IV, cap. XI, p. 122

(10) OE, op. cit., Livro IV, cap. XIII, p. 135: “...ueẽdo como a boa andãça do mũdo nõ era uerdadeyra, leixou [toda] a ponpa do segre e fez-sse mõge. E ueerõ os seus e quiserõ-no tyrar da hordem, queyxando-sse porque leixara tam nobres vestires e tantas riquezas e tam grande poder e se uestira ẽ auito tã uil. E elle lhes disse que milhor era [ẽ] panos viis auer saude pera sua alma ca ẽ panos de sirgo gaanhar cõdenaçom pera senpre."

(11) Neste passo ecoa Job 1, 21: Saí nu do ventre da minha mãe e nu voltarei para ele. O Senhor mo deu, o Senhor mo tirou:

(12) OE, op. cit., Livro IV, cap. XVIII, p.156: "E como quer que a çugidade da luxuria regna ẽ todolos sentidos do corpo, pero muyto mays ẽna vista, ca o tangimẽto tan solamẽte recebe a blandeza da carne e o ouvydo recebe da mulher e das especias ou de fumaduras, e o gosto, ẽ comẽdo cõ a molher, nõ recebe della nehũa cousa senõ tan solamente o sabor das cousas que come cõ ella, mas a vista recebe della a fegura e a collor e o gesto e o afeitamẽto e todos os mẽbros e toda a desposiçom do corpo. $\mathrm{E}$ todas estas cousas quanto mais som, tanto mais acende[m] a maa cobiça, asy como a lenha quanto mais he, tanto mais faz mayor fogo."

(13) OE, op. cit., Livro IV, cap. XX, p. 162: "E assy deue fazer todo homẽ: çarre suas orelhas, ẽ guisa que nõ ouça as palavras doces dos louuaminheyros que enganõ os homẽẽs con palauras brandas, asy como fazem as sereas cõ seus cantares."

(14) Job 8, 21: Ele encherá a tua boca de sorrisos, e de júbilo os teus lábios.

(15) Relação ambivalente que a exposição Arte Médica e Imagem do Corpo. De Hipócrates ao final do século XVIII, bem como o seu belíssimo catálogo (Lisboa: BN.) captam.

\section{Bibliografia}

Askins, A. L.-F.; Dias, A. \& Sharrer, H. L. (2002). Fragmentos de Textos Medievais Portugueses da Torre do Tombo. Lisboa: IAN/TT.

Callois, R. (1988). L'homme et le sacre, Paris: Gallimard.

Cardoso, A.; Oliveira, A. B. de \& Marques, M. S. (2010). (coords.). Arte médica e Imagem do Corpo. De Hipócrates ao final do século XVIII. Lisboa: BNP.

Koldeweij, J.; Vandenbroeck, P. \& Vermet, B. (2005). Hieronymus Bosch El bosco. Obra completa. (trad. de Marta Pérez Sánchez) Barcelona: Ediciones Polígrafa.

Le Goff, J. \& Truong, N. (2005). Uma história do corpo na ldade Média (trad. de Telma Costa), Lisboa: Teorema.

Maler, B. (ed.) (1956). Orto do Esposo, Rio de Janeiro: Ministério da Educação e Cultura. 